\title{
Effect of vacuum impregnation on the phenolic content of Granny Smith and Stark Delicious frozen apple $c v v$
}

\author{
Giampaolo Blanda $\cdot$ Lorenzo Cerretani $\cdot$ \\ Alessandra Bendini $\cdot$ Andrea Cardinali • \\ Andrea Scarpellini · Giovanni Lercker
}

Published online: 28 September 2007

(C) Springer-Verlag 2007

\section{Erratum to: Eur Food Res Technol DOI 10.1007/s00217-007-0624-x}

The original version of this article unfortunately contained errors. In the "Results and discussion" section, page 5 of the paper, line 26, value 520.58 must be substituted with value 52.058 .

The captions of Table 1-3 were incorrect. The correct versions are given below.
The online version of the original article can be found under doi: 10.1007/s00217-007-0624-x.

G. Blanda $(\bowtie) \cdot$ L. Cerretani $(\bowtie) \cdot$ A. Bendini $\cdot$ A. Cardinali

A. Scarpellini - G. Lercker

Dipartimento di Scienze degli Alimenti,

Università di Bologna, P.zza Goidanich 60 ,

47023 CESENA (FC), Italy

e-mail: giampaolo.blanda2@unibo.it

L. Cerretani

e-mail: lorenzo.cerretani2@unibo.it
- Table 1. Data of $o$-diphenol and ABTS assay must be considered one order of magnitude less (one tenth)

- Table 2. Phenolic content data and standard deviation must be considered one order of magnitude less. RED\% remain the same

- Table 3. Phenolic content data and standard deviation must be considered one order of magnitude less. RED\% remain the same 